\title{
Preface to the New Edition
}

Since our book first appeared in I991, the pests-versus-pesticides predicament has both improved and deteriorated. The good news is that many more products have appeared on the market for people wishing to avoid toxic chemicals. Garden centers, hardware stores, and the Internet commonly offer tiny game hunting products, from insecticidal soaps and repellent sprays to low-toxicity dusts and traps. Insectaries that breed beneficial insects are more numerous, and scientists are working on new ways to battle insects with biological controls that affect only the targeted pest. Organic food is less of a novelty, and organic farmers have proven that their yields can equal or exceed conventional yields.

The bad news, however, keeps getting worse. As our groundwater and air are increasingly tested, and as more scientific studies appear, we are beginning to get a glimpse of the devastating consequences of the flood of toxins that have been, and continue to be, poured, sprayed, squirted, and pumped over the earth. The dangerous deception that these chemicals will not harm us is becoming more and more apparent.

Yet the deluge is growing, not lessening. In the United States, an incredible 4.5 billion pounds of pesticides are used each year. In California, according to the Los Angeles Times, application of toxic compounds more than doubled between 1991 and 1995. Is it doing any good? American farmers are spraying two to five times more than they did thirty years 
ago, some say tenfold since World War II. Yet the loss of crops to insect damage has risen from 7 to 13 percent.

Is the government capable of protecting us? The number of "secret" inert ingredients (ones that don't have to be listed on labels) in pesticides has doubled in ten years. Inert ingredients are sometimes more toxic than the active ingredient in a pesticide. What you don't know can hurt you.

World Resources Institute issued a report warning that exposures to pesticides pose a serious public health threat by depressing the immune system. In the past few years, pesticides have also been implicated in the disruption of endocrine systems and hormone function. Scientists have noted the feminization of animals, from alligators in Florida to polar bears in the Arctic. Human sperm counts have declined between 33 and 42 percent in the past fifty years, according to some European studies.

The EPA has identified as potential human carcinogens ninety-six pesticides currently in use. Rates of certain cancers, such as testicular and prostate cancer, have increased alarmingly. In 1960, one in twenty women found themselves with breast cancer; now it is one in eight. Last year, Parkinson's was added to the list of diseases attributed to pesticide exposure. And pesticides are now known to interfere with neurological development in children.

Humans are not, of course, the only victims. Researchers at Cornell have estimated that more than 67 million birds are killed each year by pesticides applied legally to U.S. farmland. Fish also die by the millions, as do bees necessary for pollination.

But we humans can take action. As consumers, we play an important role in our profit-driven society, and we can help turn the tide. So take the time to learn about the pests that plague you and choose the safest way to manage them.

We give you the tactics; we trust in your success. 